\title{
The occurrence of test anxiety in student nurses in selected nursing schools in Ghana
}

\author{
Samuel Atindanbila ${ }^{1}$, Edward Abasimi ${ }^{2}$, Kingsley Nyarko ${ }^{1}$, Johnson Atambila Adika ${ }^{3}$ \\ ${ }^{1}$ Department of Psychology, University of Ghana, Legon, Ghana \\ ${ }^{2}$ School of Medicine and Health Sciences, University for Development Studies, Tamale, Ghana \\ ${ }^{3}$ Institute of Continuing \& Distance Education, University of Ghana, Legon, Ghana
}

\section{Email address:}

atindanbila@gmail.com (S. Atindanbila), abasimieddie@yahoo.com (E. Abasimi), kingpong37@yahoo.com ( K. Nyarko), adikatar@yahoo.com (J. A. Adika)

\section{To cite this article:}

Samuel Atindanbila, Edward Abasimi, Kingsley Nyarko, Johnson Atambila Adika. The Occurrence of Test Anxiety in Student Nurses in Selected Nursing Schools in Ghana. American Journal of Applied Psychology. Vol. 3, No. 1, 2014, pp. 21-26.

doi: 10.11648/j.ajap.20140301.14

\begin{abstract}
This paper examined the occurrence of test anxiety among student nurses in selected Nursing Schools in Ghana. A total of one hundred and sixty four student nurses $(\mathrm{N}=164)$ were drawn from five Nursing Training Schools in Ghana using stratified sampling technique. The Westside Test Anxiety Scale was administered to students from the various schools who came to Pantang Psychiatric Hospital for affiliation. Results were analysed using the independent t test and ANOVA. The findings of the study revealed that there was no significant difference in test anxiety among the various ages of the students. Secondly, there was no significant difference in anxiety scores among males and females. Thirdly, there was no significant difference in test anxiety between Christians and Muslims. There was also a significant difference in test anxiety levels among the various types of training with Health Assistant Clinical (HAC) students reporting higher test anxiety compared to both Registered General Nursing (RGN) and Midwifery students. The final finding was that there was a significant difference in reported test anxiety levels among students from the various schools with those from private institutions reporting significantly higher levels. It was recommended that the various HAC schools should organised training programmes for students on how to prepare and take exams and tests successfully.
\end{abstract}

Keywords: Test Anxiety, Selected Nursing Schools, Student Nurses

\section{Introduction}

Testing in the forms of examinations, interim assessments and practical form an integral part of the educational process of the Nursing Schools in Ghana. Unfortunately testing can be intimidating to the point that they can change a student's life forever on campus or even after graduating. It is natural to be anxious and apprehensive about important events in one's life. There is no gainsaying that exams are important to the candidate since they can make a difference in one's life and future.

In view of this, exam candidates become a bit nervous when taking tests which is normal, but that apprehension usually disappears once they become focused on and involved in the test. This kind of mild test anxiety is easily overcome and rarely affects the final results of the test.

However, in more extreme cases, the anxiety experienced by the candidate affects the student's final scores more than his or her knowledge of the topic being tested. The test anxiety is in two forms: Anticipatory and situational. The first one is experienced before the day of the exam and the situational one is experienced in the course of the exam.

According to Atindanbila (2000) test anxiety like any form of anxiety produces symptoms that affect one's physical, mental, social and spiritual life. The physical ones include headaches which are not relieved by the use of analgesics, loss of appetite and nausea, easy fatigability, rapid breathing and palpitations and poor concentration leading to "misfiring of questions" in exams. Some mental or psychological signs include thoughts focused on negative past experience, inability to understand what one is reading on the exam, inability to organize one's thoughts in order to answer the questions and inability to remember subjects even though one has studied them thoroughly and poor sleep pattern. All these signs affect the candidate socially and spiritually in several ways including the fact that some tend 
to be very religious with the hope of overcoming their problems while others think life is meaningless.

Some candidates also become depressed and are self-centred whilst others become very irritable upon the least provocation.

The effects of test anxiety on academic performance have been widely recognised and research (e.g. Capell, Blanding, Silverstein, Takahashi Newman, Gubi and McCann, 2005). In addition, anxiety in general has been found to correlate with various variables such as age, gender and religion. However little is known about the relationship between test anxiety and such variables among nursing students in various nursing schools in Ghana. The present study thus aims at investigating the occurrence of test anxiety among nursing students with regards to socio- demographic variables such as age, gender, religion and type of training.

\section{Objectives of the Study}

The study is mainly aimed at investigating the occurrence of test anxiety among nursing students with regards to their socio- demographic variables such as age, gender, religion and type of training. To enable the researchers realise this objective, the following specific objectives were set:

1. to examine the incidence of test anxiety among the various ages of the students

2. to find out the distribution of test anxiety among the gender of the students

3. to determine the distribution of test anxiety among the religion of the students

4. to find out the distribution of test anxiety among the types of training of the students

\section{Hypotheses}

Based on the above objectives, the following hypotheses are tested:

1. There will be a significant difference in the level of test anxiety among various ages of the students in the selected schools

2. There will be a significant difference in the level of test anxiety among students with regards to their gender

3. There will be a significant difference in the level of test anxiety among students with regards to their religion

4. There will be a significant difference in the level of test anxiety among students with regards to the type of training.

5. There will be a significant difference in the level of test anxiety among students with regards to their various schools.

\section{Review of Relevant Literature}

Test anxiety has been defined as "the set of phenomenological, physiological and behavioural responses that accompany concern about possible negative consequences or failure on an exam or similar evaluative situation"
(Zeidner, 1998, p.17). A number of research studies reveal that test anxiety is influenced by a number of socio-demographic and other factors such as participants' age, gender and religion. For example, Whitbourne (1976) in a study on test anxiety in elderly and young adults found that the elderly had higher levels of debilitating test anxiety than the younger adults. According to the study many of the elderly showed many behavioural manifestations of test anxiety by either refusing to participate in the study or by their reactions during the study.

In a study by Capell, Blanding, Silverstein, Takahashi Newman, Gubi and McCann (2005), testing the relationship between test anxiety and academic performance, it was found among others that gender significantly influenced test anxiety. Specifically, the findings showed that female undergraduates and post graduates had significantly higher test anxiety than male undergraduates and post Graduates. Generally, results indicate that test anxiety is associated with reductions in GPAs at both educational levels. El-Zahhar and Hocevar (1991) also found that high school females experienced greater test anxiety in three different cultures including Egypt, Brazil and the United States of America than males.

Cultural differences have been found to influence anxiety generally and specifically test anxiety. In the study by El-Zahhar and Hocevar(1991), cultural and sexual differences were investigated in samples of high school students. Using measures of test anxiety, trait anxiety and trait arousability, greater test anxiety were found in Egypt on both the worry dimension and emotionality dimension when compared to the United States. Greater test anxiety was also found in Brazil compared to the United States but only on the emotionality component. The study also revealed that compared to both Brazil and the United States, greater trait anxiety, and arousability was reported by high school students in Egypt. Since religion is a component of culture, it can be deduced that religion would independently influence the level of test anxiety.

Anxiety in general has correlated both positively and negatively with religion in past research. Some studies ( e.g. Tanset, 1976, Entner, 1977) have found religion to be related to lower anxiety whiles many others have found religion to be associated with better psychological adjustment(e.g. Mayco, Puyear \& Richeck, 1969; Langner, Michael, \& Opler, 1962) . However, little is known about the relationship between test anxiety and religion. According to Baker and Gorsuch(1982), who studied subjects from the Religious wilderness camping organisation in Southern California, the confusion conclusions on the relationship between anxiety and religion may be due to the use of undifferentiated measures of both religion and anxiety. They concluded that when intrinsic and extrinsic religious scales were used with Cattel's factors of trait anxiety, intrinsics were less anxious than non- extrinsics and extrinsics were more anxious than non-extrinsics on some, but not all, components of trait anxiety. They also concluded that studies using general measures of religiousness would have a positive correlation 
with anxiety if the sample contained more extrinsics than intrinsics and a negative relationship if the sample contained more intrinsics than extrinsics. They also stated that no relationship would be found if an inappropriate component of anxiety was measured.

Intrinsically religious individuals are those who see religion as an "end" and extrinsically religious individuals are those who use religion as a "means" to an end. The researchers used the Religious Orientation Scale of Allport and Ross (1967) to measure religiousness and the IPAT Anxiety scale to measure trait anxiety.

\section{Methodology}

This study was done on Affiliates from five schools that came to Pantang Hospital for a six week Psychiatric affiliation. These schools included Ho, Sunyani, Offinso, Health Concern and Atibie. The 164 respondents were chosen through stratified sampling in the five institutions. It took them twenty minutes to answer the questions and they were collected back. In view of this the response rate was $96 \%$.

\subsection{Research Design}

Since the study was aimed at finding out the opinions of the student nurses on their perceptions of their anxiety towards exams, the cross-sectional survey research was used since it is the most appropriate technique.

\subsection{Instrument}

The Westside Test Anxiety Scale was used for the study. It is used to identify students with anxiety impairments. The instrument scale is comprised of ten items, and takes about five to eight minutes to administer. It has been used by school counsellors over several years and has six items assessing impairment and four items on worry and dread in students. According to Driscoll (2004), the Westside Test Anxiety Scale is a reliable and valid measure of test-anxiety impairment and since it is brief and easily administered; its use should be encouraged by researchers. The norms are as follows:

$1.0-1.9$ Comfortably low test anxiety

$2.0-2.5$ Normal or average test anxiety

2.5-2.9 High normal test anxiety

3.0 - 3.4 Moderately high (some items rated 4=high)

3.5-3.9 High test anxiety (half or more of the items rated $4=$ high)

4.0 - 5.0 Extremely high anxiety (items rated $4=$ high and $5=$ extreme)

\section{Results}

This study was aimed at finding out the test anxiety among Nursing students at selected schools in Ghana. Based on this, four hypotheses were formulated. The details of the analyses of the data and the summary tables of the descriptive statistics for the variables studied are provided below.

\subsection{Hypotheses Testing}

The first hypothesis stated that there will be a significant difference in the level of test anxiety among various ages of the students in the selected schools. The independent samples t-test was used to analyse because the mean scores of anxiety levels of the two different age groups are compared. The table below shows a summary of the results obtained.

Table 1. A summary of Means, Standard Deviations and t-test of the Levels of Test Anxiety Among the Ages of the Students.

\begin{tabular}{ccccccc}
\hline Age & $\mathbf{N}$ & $\boldsymbol{M}$ & $\boldsymbol{S D}$ & $\boldsymbol{d f}$ & $\boldsymbol{t}$ & $\boldsymbol{S}$ Sig \\
\hline $20-24 \mathrm{yrs}$ & 131 & 1.82 & .65 & 151 & .22 & .642 \\
$25-29 \mathrm{yrs}$ & 22 & 1.75 & .45 & & & \\
\hline
\end{tabular}

The above table shows that the mean difference in the levels of test anxiety of students with ages between $20-24 y r s(\mathrm{M}=1.82, \mathrm{SD}=.65)$ and $25-29 \mathrm{yrs}(1.79, \mathrm{SD}=.45)$ was found not to be statistically significant $(t=.22, d f=151$, $p=.642$, 0ne tailed). The above hypothesis has therefore been rejected.

The second hypothesis tested stated that there will be a significant difference in the level of test anxiety among students with regards to their gender. The independent samples t-test was used because the mean scores of anxiety levels of males and females were compared. The table below shows a summary of the results obtained.

Table 2. A summary of Means, Standard Deviations and t-test of the Levels of Test Anxiety among Male and Female Students.

\begin{tabular}{ccccccc}
\hline & $\mathbf{N}$ & Mean & $\boldsymbol{S D}$ & $\boldsymbol{d f}$ & $\boldsymbol{t}$ & $\boldsymbol{S i g}$ \\
\hline Male & 30 & 1.93 & .64 & 162 & 1.28 & .259 \\
Female & 134 & 1.79 & .64 & & & \\
\hline
\end{tabular}

Table 3. A summary of Means, Standard Deviations and t-test of the Levels of Test Anxiety Among Christian and Muslim Students.

\begin{tabular}{ccccccc}
\hline Religion & $\boldsymbol{N}$ & $\boldsymbol{M}$ & $\boldsymbol{S D}$ & $\boldsymbol{d f}$ & $\boldsymbol{t}$ & Sig \\
\hline Christian & 157 & 1.81 & 62 & 160 & 70 & .405 \\
Muslim & 5 & 2.05 & 53 & & & \\
\hline
\end{tabular}

The above table shows that the mean difference in the levels of test anxiety of males $(\mathrm{M}=1.93, \mathrm{SD}=.64)$ and females $(1.79, \mathrm{SD}=1.28)$ was found not to be statistically significant ( $t=1.28, d f=162, p=.259$, 0ne tailed ). The above hypothesis has therefore been rejected.

The third hypothesis tested stated that there will be a significant difference in the level of test anxiety among 
students with regards to their religion. The independent samples t-test was used because the mean scores of anxiety levels of students of the two religions are compared. The table below shows a summary of the results obtained.

The above table shows that the mean difference in the levels of test anxiety of Christian students $(M=1.81, S D$ $=.62)$ and Muslim $(\mathrm{M}=2.04, S D=.53)$ was found not to be statistically significant $(t=.70, d f=160, p=.405$, 0ne tailed). The above hypothesis has been rejected.

The fourth hypothesis tested the differences in the levels in test anxiety in the various types of training in nursing. This hypothesis was tested using the One-Way Analysis of Variance because the mean scores of the test anxieties of the three various types of training in nursing are compared. The results are shown below.

Table 4. A summary of Means, Standard Deviations and F-test of the Levels of Test Anxiety Among Midwifery, RGN and HAC Students.

\begin{tabular}{cccccccc}
\hline Students & $\boldsymbol{N}$ & $\boldsymbol{M}$ & $\boldsymbol{S D}$ & $\boldsymbol{d} \boldsymbol{f}$ & $\boldsymbol{F}$ & $\boldsymbol{P}$ & $\eta^{2}$ \\
\hline Midwifery & 41 & 1.85 & .68 & 2,161 & 7.12 & .001 & .081 \\
RGN & 64 & 1.60 & .46 & & & & \\
HAC & 59 & 2.01 & .66 & & & & \\
\hline
\end{tabular}

The results above show that there is a significant difference in the level of anxiety among the various types of training in nursing $\left[\mathrm{F}(2,161)=7.12, \mathrm{p}=.001,=\eta^{2} .081\right.$, two tailed ].

In view of the outcome above, a post hoc comparison was employed using the Bonferroni test which indicated that students in HAC $\quad(\mathrm{M}=2.01, \mathrm{SD}=.66)$ had more test anxiety as compared to the rest of the schools which had similar levels of test anxiety. The above hypothesis has been supported.

The last hypothesis seeks to find out the difference in the level of test anxiety among students with regards to the various schools. This hypothesis was tested using the One-Way Analysis of Variance because the mean scores of the test anxieties of the five various schools of training in nursing are compared. The results are shown below.

Table 5. A summary of Means, Standard Deviations and F-test of the Levels of Test Anxiety Among Students of the Seven Schools.

\begin{tabular}{cccccccc}
\hline & $\mathbf{N}$ & Mean & SD & df & $\boldsymbol{F}$ & Sig & $\eta^{2}$ \\
\hline Health C & 59 & 2.01 & 66 & 4,141 & 3.70 & .002 & .124 \\
Offinso & 23 & 2.03 & 75 & & & & \\
Sunyani & 35 & 1.65 & 52 & & & & \\
Ho & 21 & 1.43 & 19 & & & & \\
Atibie & 18 & 1.63 & 51 & & & & \\
\hline
\end{tabular}

The results above show that there is a significant difference in the level of anxiety among the various schools of training in nursing $\left[\mathrm{F}(4,141)=3.70, \mathrm{p}=.002, \eta^{2}=.124\right.$, two tailed].

In view of the outcome above, a post hoc comparison was employed using the Bonferroni test which indicated that students in Health Concern ( $\mathrm{M}=2.01, \mathrm{SD}=.66$ ) and Offinso $(\mathrm{M}=2.03, \mathrm{SD}=.75)$ had more test anxiety as compared to the rest of the schools which had similar levels of test anxiety. The above hypothesis has been accepted.

\section{Discussion}

This study sought to examine the occurrence of test anxiety among student nurses of selected nursing training colleges in Ghana. Based on this general objective, four specific objectives were formulated by the researchers. The first objective is to examine the incidence of test anxiety among the various ages of the students. The second one is to find out the distribution of test anxiety among the gender of the students whiles the third is to determine the distribution of test anxiety among the religion of the students. The last objective sought to find out the distribution of test anxiety among the types of training of the students.

Based on the forgoing objectives, a number of hypotheses were formulated and tested. The results obtained were therefore based on the objectives and hypotheses tested. The following discussion is therefore based on the objectives of the study.

The first objective of the study was to find out the distribution of test anxiety among the various ages of the students. There was no statistically significant difference between the various ages of the students. Students in the age bracket of 20-24yrs and 25-29yrs experienced similar levels of anxiety. This result seems to be inconsistent with past research. For example it is inconsistent with the findings of Whitbourne (1976) who found that elderly adults experienced higher levels of debilitating anxiety compared to their younger counterparts.

The second objective aimed to examined whether a significant difference exist in the level of test anxiety among students with regards to their gender. The finding of the study revealed no significant difference between male and female students with regards to the level of anxiety they experienced. This finding is inconsistent with previous finding on the relationship between test anxiety and gender. For example it is inconsistent with the findings of Capell et al. (2005) and El-Zahhar and Hocevar(1991) both of which found that females experienced higher test anxiety than males. A critical examination of the sample could help us explain why the result of the current study is so. Nursing has predominantly been a female profession and this is reflected in the sample of 134 females against 30 males for the current study. Since the sample consisted mainly of females, there is little or no competition with males for higher academic achievement on the part of the females. The existence of keen competition between males and females could have resulted in the experience of higher anxiety by the female students.

The findings of the study also failed to support the third hypothesis which is based on the third objective aimed at determining the level of test anxiety among Christians and 
Muslims. The third hypothesis stated that there will be a significant difference in test anxiety between Christians and Muslims. However, the findings revealed no significant difference between the two religious groups. This result seems to be a new finding since researchers did not come across past research on the relationship between test anxiety and religion. Previous research have examined the relationship between anxiety in general and religion and have found inconsistent results with some researchers finding religion to be related to lower anxiety ( e.g. Tanset, 1976, Entner, 1977) whiles others find it to be associated with better psychological adjustment (e.g. Mayco, Puyear \& Richeck, 1969; Langner, Michael, \& Opler, 1962). However Baker and Gorsuch(1982) have provided explanations as to why the confusion findings exist. According to them the differences exists due to the use of undifferentiated measures of anxiety and religion.

The fourth objective from which the fourth hypothesis was derived sought to examine test anxiety among students with regards to type of training. The question was whether there would be differences in levels of test anxiety among the Midwifery, RGN and HAC students. The findings of the study revealed that a significant difference exist among the groups with HAC students experiencing more test anxiety compared to both midwifery and RGN students. This finding may not be very surprising since according to past research younger and inexperienced students are more likely to be stressed than their more experienced counterparts. The students from the HAC programme are the lowest of the three in terms of their academic achievement and this alone can put some form of anxiety on them since they have to study the same thing at the Psychiatric hospital with their senior counterparts since they were all on psychiatric affiliation. They are also more likely to be looked down upon by their colleagues who are offering midwifery and RGN. One could also speculate that it was the high test anxiety level of students offering the HAC programme that led to their previous low academic achievement at the senior high schools which fail to qualify them for either the RGN or the midwifery programmes whose requirements are higher.

Finally, as stated above, the current study tested whether there would be a significant difference in the level of test anxiety among students with regards to their various schools of training. Participants were drawn from five training colleges including Ho, Sunyani, Offinso, Attibie and Health Concern. The findings of the study revealed significant differences among the groups with students from Health Concern and Offinso experiencing significantly higher anxiety levels compared to the other three which had similar levels of anxiety. This result is not very surprising since out of the five institutions, only Offinso and Health Concern are private institutions. They are therefore more likely to be stricter and thus put more demands on their students compared to the other three which are public institutions and may be comparatively relaxed in terms of discipline and the demands to achieve certain standards. In general private institutions usually want to make a mark by raising their standards so as to attract more students in the future and are therefore likely to put certain measures in place to achieve such standards. This could in turn put students under unexpected stress leading to anxiety.

\section{Recommendations}

Based on the findings of the present study, a number of recommendations are made which are outlined below.

The finding that the students in the HAC programme report higher test anxiety might imply they have problems taking exams or are inappropriately prepared for it. It is therefore recommended that the various HAC schools should organised training programmes for students on how to prepare and take exams and tests successfully.

Secondly, the finding that students from private training institutions report higher test anxiety will call for strategies to mitigate the anxiety and possible stress levels of students. Management of such training institutions should therefore conduct studies into the causes of such test anxiety and therefore find ways of mitigating them.

\section{Conclusion}

The present study sought to examine the occurrence of test anxiety among student nurses of selected nursing training colleges in Ghana. Four specific objectives were formulated by the researchers. The first objective is to examine the incidence of test anxiety among the various ages of the students. The second one is to find out the distribution of test anxiety among the gender of the students whiles the third is to determine the distribution of test anxiety among the religion of the students. The last objective sought to find out the distribution of test anxiety among the types of training of the students.

Based on the above objectives five hypothesis were tested. The finding revealed that firstly there was no significant difference in test anxiety in the various ages of the students. Secondly, there was no significant difference in anxiety scores among males and females. Thirdly, the results showed no significant difference between Christians and Muslims. The next finding showed that a significant difference exist in anxiety levels among the various types of training. Specifically, HAC students reported higher test anxiety compared to both RGN and Midwifery students. The final finding was that there was a significant difference in reported anxiety among students from the various schools with students from private institutions such as Health Concern and Offinso reporting significantly higher anxiety. Recommendations were made based on these findings as follows.

It was firstly recommended that training programmes be organised for students from the HAC schools to prepare them on how to take exams and test. Secondly, it was recommended that management of private nursing training institutions shouldd conduct studies into the causes of test anxiety and find ways of mitigating them. 


\section{References}

[1] Allport, G. \& Ross, J. (1967). Personal religious orientation and prejudice. Journal of Personality and Social Psychology 5(4), 431-443.

[2] Atindanbila, S. (2000). The stress and coping strategies of lecturers at the University of Ghana Unpublished PhD Dissertation presented to the University of Ghana as partial requirement for the award of $\mathrm{PhD}$ degree.

[3] Baker, M., \& Gorsuch, R. (1982). Trait Anxiety and Intrinsic-extrinsic Religiousness. Journal for scientific study of religion, 21(2), 199-122

[4] Capell, M.S., Blanding, Z.B., Silverstein, M.E., Takahashi, M., Newman, B., Gubi, A. \& McCann, N. (2005). Test anxiety and academic performance in Undergraduate and Graduate students. Journal of Educational Psychology, 97(2), 268-274

[5] El-Zahhar, N. E. (1991). Cultural and Sexual differences in

Test Anxiety, Triat Anxiety and Arousability in Egypt, Brazil, and the United States. Journal of Cross- Cultural Psychology, 22(2), 238-249

[6] Gorsuch, R. (1976). Religion as an significant predictor on important human behaviour. In W. Donalson, Jr.(Ed.). Research in Mental Health and Religious behaviour. Psychological studies institute.

[7] Mayco, C.M, Puryear, H., \& Richek, H. (1969). MMPI correlates of religiousness in late adolescent college students. Journal of Nervous and mental disease, 149, 381-385.

[8] Silva, R. R. , Gallagher, R., Minami, B.A.(220). Cognitive -Behavioural treatments for Anxiety Disorders in Children and Adolescents. Primary Psychiatry, 13 (5) 68-76

[9] Whitbourne, S.K.(1976). Test anxiety in Elderly and Young Adults. The Journal of Aging and Human Development,7(3), 201-210.

[10] Zeidner, M.(1998). Test anxiety: The state of the art. New York: Plenum Press. 